\title{
Interactions Between Weedy Rice and Cultivated Rice in Italy
}

\author{
Francesco Vidotto*, Aldo Ferrero \\ ${ }^{1}$ Dipartimento di Agronomia, Selvicoltura e Gestione del Territorio, Università di Torino \\ Via Leonardo da Vinci 44, 10095 Grugliasco (TO), Italy
}

Received: 30 January 2009. Accepted: 11 September 2009.

\begin{abstract}
Field studies were carried out in 1997 and 1998 in northwest Italy with the aim of determining the effects of weedy rice competition on rice growth dynamics and yield. 'Arborio' (medium-high tall size, high early vigour) and 'Thaibonnet' (semi-dwarf size, low early vigour) rice cultivars were grown in competition with weedy rice at four densities $\left(0,10,20\right.$, and 40 plants $\left.\mathrm{m}^{-2}\right)$. For both cultivars the plant height, the aboveground biomass and the number of tillers were determined at different intervals. With some exceptions, all the measured rice growth parameters were not remarkably affected by weedy rice interference. Weedy rice plants grown in competition with 'Arborio' were generally taller and produced more biomass. Weedy rice competition resulted in up to $50 \%$ (in 'Thaibonnet') and $48 \%$ (in 'Arborio') yield losses. The yield losses observed in both varieties were primarily related to the reduction of yield components, and of panicle density and number of filled grains per panicle, in particular.
\end{abstract}

Key-words: competition, red rice.

\section{Introduction}

Rice (Oryza sativa L.) production throughout the world is affected by weeds of the genus Oryza L., such as O. sativa L., O. barthii A. Chev., O. longistaminata A. Chev. \& Roehr., $O$. officinalis Wall. ex Watt., O. punctata Kotschy ex Steud., and O. rufipogon Griff. (Harlan, 1973; Hoagland and Paul, 1978; Dadi and Engels, 1986; Katayama and Sumi, 1995; Holm et al., 1997). Most of these species share important morphological and biological traits such as high competitiveness and shattering ability. In addition, some of them have grains with the pericarp pigmented in red due to the presence of anthocyanin. This in particular is the case of many weedy forms of $O$. sativa, which are commonly called "red rice". The same term is also sometimes used to refer to weedy forms of other species, such as $O$. glaberrima, $O$. longistaminata, O. punctata, and O. rufipogon (Jairo Clav- ijo and Baker, 1988; USDA and ARS, 2001). The term "weedy rice" has recently been adopted by some authors (Federici et al., 2001) and has also been recommended during a specific FAO meeting (FAO, 2000) to refer to the whole group of species that belong to the genus Oryza and behave as weeds of rice or other crops.

O. sativa is considered to be the main weedy rice species in some temperate climatic paddy field areas of America and Europe (Diarra et al., 1985a, 1985b; Ferrero et al., 1999).

Compared to cultivated varieties, weedy forms of $O$. sativa usually show numerous and slender tillers, more hispid and light green leaves, taller plants and marked shattering capacity of the grains (Hoagland and Paul, 1978; Baker et al., 1986; Kwon et al., 1992; Tarditi and Vercesi, 1993).

Weedy rice plants can be highly competitive against rice and can cause severe yield losses, in relation to density, population, and cultivated 
variety (Diarra et al., 1985a, 1985b; Fischer and Ramirez, 1993). Several studies have been carried out to assess the effects on rice yield of different weedy rice densities. With 11 weedy rice plants $\mathrm{m}^{-2}$, Abud (1989) observed a yield loss of about $43 \%$. In studies conducted in Arkansas, the yield of semi-dwarf cultivar Lemont was already affected at a weed density as low as two plants $\mathrm{m}^{-2}$ (Kwon et al., 1991a). Five and 20 plants $\mathrm{m}^{-2}$ of weedy rice caused a yield loss of 40 and $60 \%$, respectively, in the cultivar Oryzica 1 (Fischer and Ramirez, 1993). Some studies pointed out that competition effects are also closely related to interference duration (Kwon et al., 1991b). Combining the effects of weedy rice density and duration of competition, Fischer and Ramirez (1993) observed a yield reduction of $50 \%$ when 24 weedy rice plants $\mathrm{m}^{-2}$ competed with the crop during the first 40 days after emergence. With the same initial density, the yield loss reached $75 \%$ in the case of seasonlong competition. In a greenhouse experiment, significant effects on rice plant growth were recorded only when the competition had a duration of longer than 70 days, starting from the emergence (Estorninos et al., 2000). The presence of weedy rice may affect several growth parameters of cultivated rice, such as plant tillering, plant height, leaf area, and shoot dry mass (Fleck et al., 2008). In studies of competition using the cultivar Mars, inter-varietal competition resulted to be more important than intra-varietal competition, with the weedy rice acting as the dominant competitor (Pantone and Baker, 1991a, 1991b).

Even though there is a great deal of information on the relationship between weedy rice density and rice yield loss, only a few studies are focused on determining how the rice plant growth dynamics are influenced by the presence of weedy rice. In most cases, the evolution over the season of the main growth-related traits (i.e. plant height, leaf area, biomass) is not considered and only in a few papers the growth of rice plant in competition with weedy rice is seen as a whole (Eleftherohorinos et al., 2002).

This paper reports the results of a two-year experiment conducted in northwest Italy with the following aims: 1) to investigate the influence of different weedy rice infestation densities on the vegetative growth dynamics and the yield of two cultivated rice varieties, character- ized by different size and earliness, and 2) to investigate the effects of the competition due to the crop and the weedy rice on vegetative growth dynamics on the weedy rice itself.

\section{Materials and methods}

The study was conducted in 1997 and 1998 at the Rice Research Center of the Ente Nazionale Risi (National Rice Agency), which is located in a typical rice cultivation area in North-West Italy (Ultic Hapludalf, coarse loamy soil). The experiment was carried out, over the two years, in two similar and adjacent fields, to avoid any emergence of weedy rice from seeds shattered during the first year. The experimental area hosted rice varietal studies for many years and had no history of weedy rice prior to the study. Yield records showed that the area was very homogeneous in terms of soil fertility. Four weedy rice $($ O. sativa $)$ densities $(0,10,20$, and 40 plants $\mathrm{m}^{-2}$ ) were tested in competition with either the variety 'Arborio' or 'Thaibonnet', chosen among the varieties cultivated in Italy for their supposedly different sensitivity to weed competition. 'Arborio' (Italian, japonica-type variety) is a medium-high tall size variety (average height $98 \mathrm{~cm}$ ) with high early vigour and cycle duration of about 150 days. 'Thaibonnet' (indica-type variety) is a semi-dwarf variety with low early vigour and cycle duration of about 160 days. The densities that were chosen are in the range of the infestation levels that usually occur in Italian rice fields, even though the density of 40 plants $\mathrm{m}^{-2}$ should be considered a high and uncommon infestation level.

The treatments resulting from the factorial combination of cultivars and weedy rice densities were arranged in plots of about $25 \mathrm{~m}^{2}$ according to a complete randomized design with 4 replications.

The experimental area was moldboard ploughed during the autumn before each year to a depth of $25 \mathrm{~cm}$ and harrowed about 10 days before seeding to prepare the seedbed.

Both the weedy rice and cultivar seeds were planted in a single operation, carried out on April 30 $0^{\text {th }}$ in 1997 and May $5^{\text {th }}$ in 1998. The seeds of straw-hulled weedy rice that were used for the experiment were collected in 1996 from mature panicles in naturally infested fields. Before 
planting, both the rice and weedy rice seeds were soaked in water for 24 hours and then sown by hand directly into the flooded paddy.

'Arborio' was seeded at $286 \mathrm{~kg} \mathrm{ha}^{-1}$ and 'Thaibonnet' at $169 \mathrm{~kg} \mathrm{ha}^{-1}$, to obtain the same seeding density of about 650 seeds $\mathrm{m}^{-2}$, as the two cultivars have a 1000 -seed weight of about $44 \mathrm{~g}$ and $26 \mathrm{~g}$, respectively. An appropriate amount of soaked seed of the weed was added and mixed to the crop seed immediately before the planting. In order to obtain the different weedy rice densities, the amount of weedy rice seed added to the crop seed was calculated taking into consideration a 1000-seed weight of 32 $\mathrm{g}$ and an average percentage of emergence of $50 \%$, which was assessed in a preliminary test (A. Ferrero, unpublished data).

All the other cultural operations were carried out according to the usual practices adopted in the area. The experimental field was continuously flooded using a flow- through system in which the water was supplied via a head ditch. The average water depth over the growing season was of about $7 \mathrm{~cm}$. The water inflow was stopped about four weeks before harvesting.

At about 10-day intervals starting from 48 (1997) or 65 (1998) days after sowing (DAS), plant samplings were made within the plots. A total of 5 samplings in 1997 and 4 samplings in 1998 were carried out. At each sampling date, three square areas of $50 \times 50 \mathrm{~cm}$ were singled out within each plot and all rice and weedy rice plants present in the squares were uprooted and placed in plastic bags that were quickly placed in the refrigerator.

Within $24 \mathrm{~h}$ from collection, plant height (from the culm base to the tip of the longest leaf) and dry weight of the above-ground biomass were assessed on 5 rice and weedy rice plants randomly chosen from each sample.

The number of tillers was also assessed at the last samplings, carried out at 99 DAS in 1997 and at 103 DAS in 1998. Data of plant measurements were averaged within each sample, thus obtaining three values for each plot and sampling date.

The panicle density of rice cultivar was assessed before harvesting in each plot by considering three square areas of $50 \times 50 \mathrm{~cm}$. Two rice panicles were collected from each of the same areas to assess the number of filled grains per panicle. Rice was harvested using an ISEKI plot combine harvester (ISEKI \& CO. Ltd, Tokyo, Japan) and the rough grain yields were adjusted to $13 \%$ moisture. The 1000 -seed weight (adjusted to $13 \%$ moisture) was assessed on paddy samples of each plot.

All the data were subjected to analysis of variance and the data of the two years and cultivars were analyzed separately, as it was already known that the two cultivars differ either in size, biomass and number of tillers (ENR, 1998).

For each year and cultivar, the data of both rice and weedy rice plant height and aboveground biomass were fitted (Curve Fitter, SigmaPlot ver. 7.0, Systat Software Inc., Chicago, USA) to the following exponential regression model, considering the days after sowing as the independent variable $(x)$ :

$$
y=y_{0}+a e^{b x}
$$

For each cultivar, the regressions that refer to $0,10,20$ and 40 plants $\mathrm{m}^{-2}$ were statistically compared by performing the lack-of-fit test (Chow, 1960; Seefeldt et al., 1995) on all possible pairs of regressions, to compare the effects on rice growth over the season. The same test was also performed to compare the growth data of the weedy rice grown in competition with either Thaibonnet or Arborio. In this case, a comparison among the densities of 10, 20 and 40 plants $\mathrm{m}^{-2}$ was made.

The following hyperbolic equation proposed by Cousens (1985) was used to describe the relationship between rice yield loss and weedy rice density:

$$
y_{L}=\frac{i D}{1+i D / a}
$$

where $y_{L}$ is percent yield loss, $i$ is percent yield loss per weed plant per unit area as weed density approaches zero, $a$ is the upper limit to percent yield loss at very high density of the weed, and $D$ is the weed density.

The relationships between yield component data of cultivars and weedy rice density were described by using the models that gave the best fitting. The panicle density and the 1000-seed weight data were fitted to the following model:

$$
y=a+b D^{c}
$$

where $y$ the panicle density or the 1000-seed weight of the cultivar, and $D$ is the weedy rice 
plant density. The number of filled grains per panicle data as function of weedy rice density was fitted to a simple linear model.

\section{Results}

Plant Height. The growth of rice and weedy rice in terms of plant height was quite different in the two seasons. On average, the values recorded during the second year were higher, in particular in the case of the cultivars. In general, the plants grown during 1998 appeared slightly slender and weaker than those grown during the previous year. The cv Thaibonnet grown with no competition with weedy rice reached a final height of about $42 \mathrm{~cm}$ in 1997 at 99 days after sowing (DAS), and $62 \mathrm{~cm}$ in 1998 at 103 DAS (Tab. 1). Plant height increase was remarkable starting from 85 DAS in 1997 and 91 DAS in 1998 (Fig. 1). In both years, the response to competition when this variety was grown alone or in competition with weedy rice was quite similar and the regressions describing the relationship between plant height and the time referred to $0,10,20$ or 40 weedy rice plants $\mathrm{m}^{-2}$ were not significantly different from one another.

The cv Arborio was always taller than Thaibonnet, and reached about $67 \mathrm{~cm}$ in 1997 and
$98 \mathrm{~cm}$ in 1998 (Fig. 1). Also in this case, a similar pattern of plant height growth was observed, regardless the weedy rice density. Taking into consideration the final plant height (99 DAS in 1997 and 103 DAS in 1998), significant differences between densities were found in 1997 only in cv Thaibonnet (Tab. 1). In this case, the rice plants grown without weedy rice competition were about $2 \mathrm{~cm}$ taller $(42.2 \mathrm{~cm})$ than the average recorded among the three weedy rice densities $(40.1 \mathrm{~cm})$, thus giving an average reduction due to competition of $5 \%$.

Weedy rice plants were always taller than cultivar ones and, as observed for both cultivars, the highest values were recorded during 1998. In both years, the intermediate and final heights were not influenced by weedy rice density, but plants grown in competition with Arborio cultivar were generally taller. This discrepancy was statistically significant for the last 3 samplings in 1997 (at 71, 85, and 99 DAS) and for all the sampling dates in 1998. The lack-of-fit test pointed out that, for both years, the data of plant height referred to weedy rice grown with Thaibonnet or Arborio cannot be described by a single curve without a significant reduction of fitting quality, suggesting that the dynamics of weedy rice growth in terms of plant height is influenced by the cultivar the weed was competing with.

Table 1. Plant height $(\mathrm{cm})$, aboveground biomass $\left(\mathrm{g}_{\mathrm{DM}}\right.$ plant $\left.^{-1}\right)$ and number of tillers per plant recorded in the two cultivars, and in the weedy rice (WR) at the last sampling dates (99 and 103 DAS in 1997 and 1998, respectively).

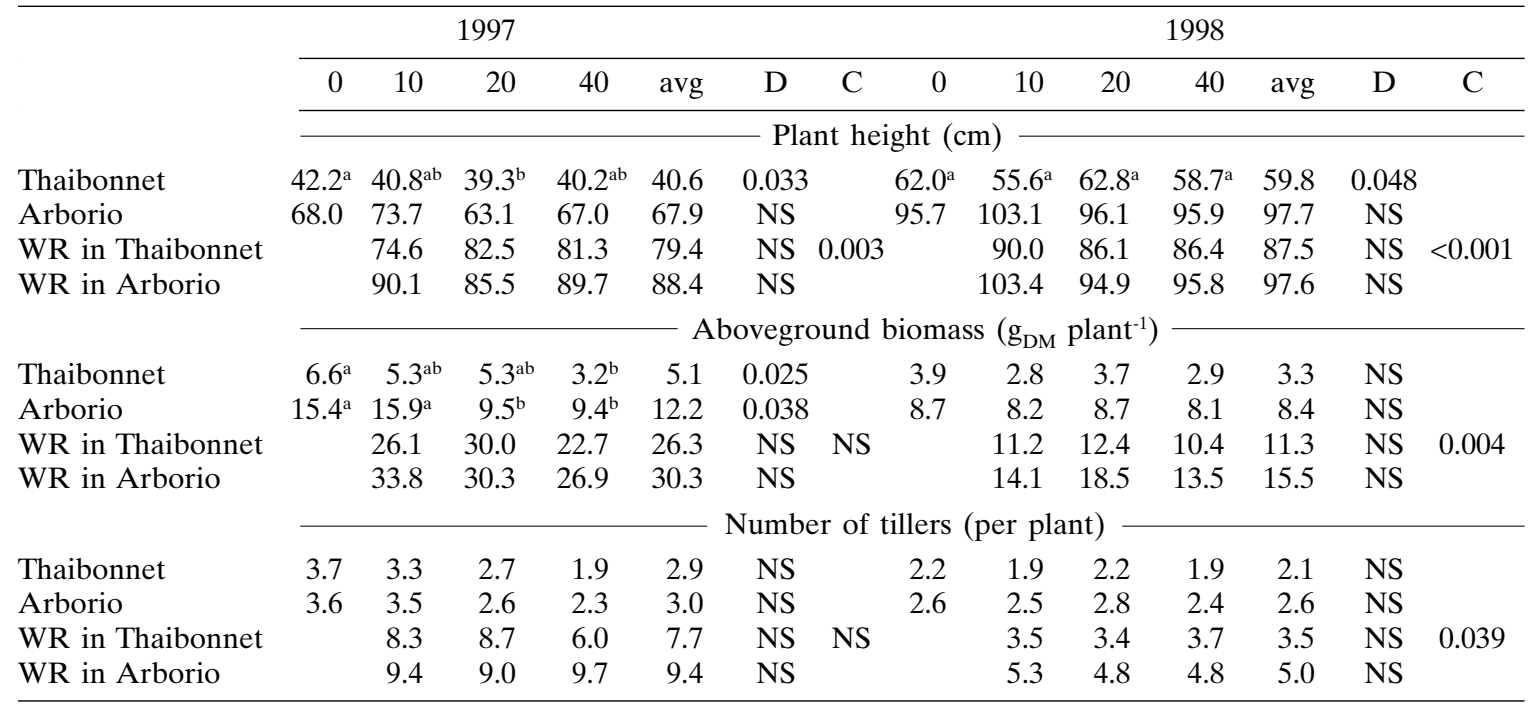

avg, average of values recorded at weedy rice density of $0,10,20$, and 40 plants $\mathrm{m}^{-2}$; $\mathrm{D}$, significance of the effect of weedy rice density on cultivated rice; $\mathrm{C}$, significance of the effect of rice variety on weedy rice. For each year, means within a row followed by the same letter are not significantly different according to Student-Newman-Keuls test $(P=0.05)$. 

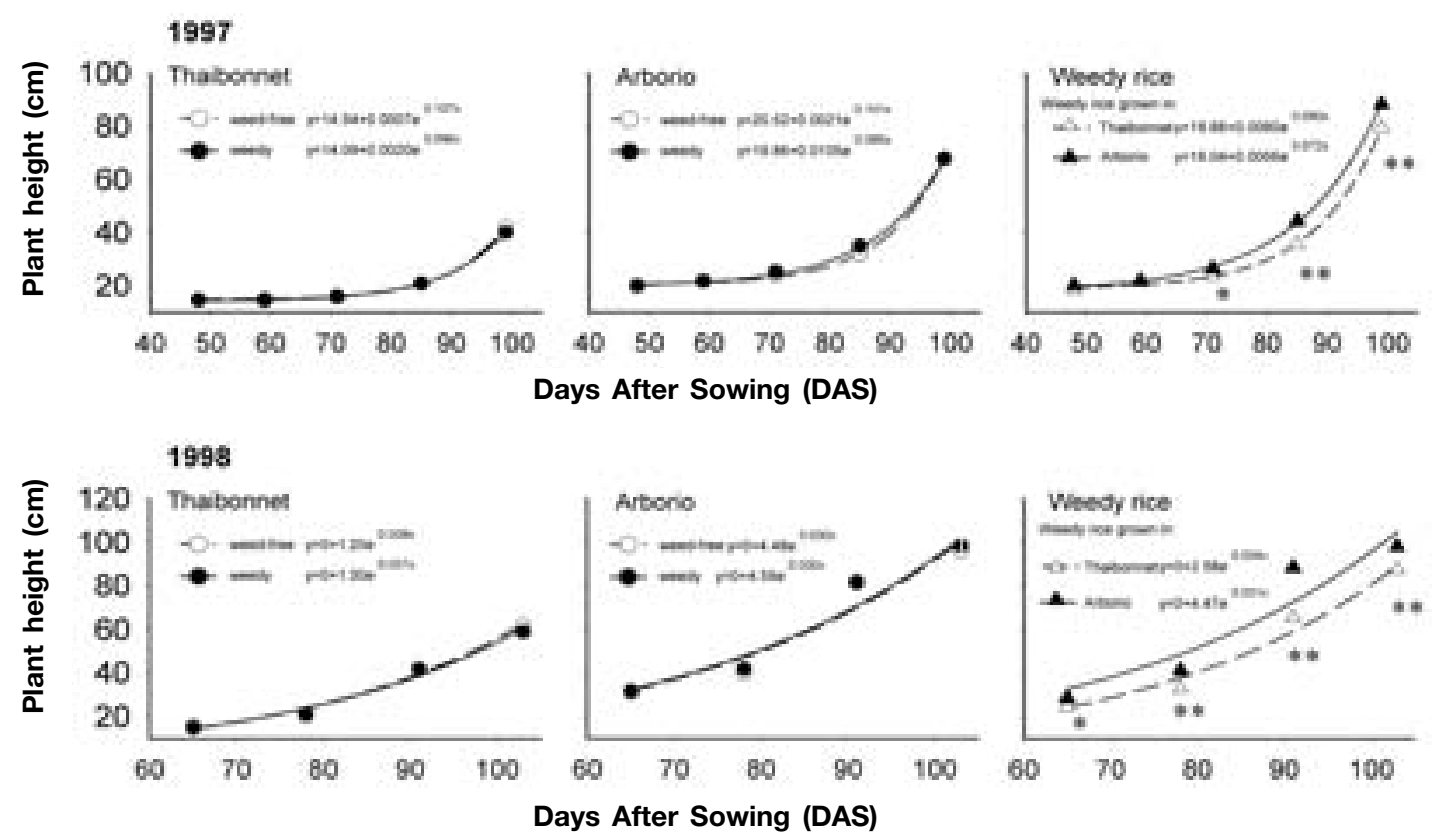

Figure 1. Plant height growth of Thaibonnet, Arborio and weedy rice in 1997 and 1998. In the case of Thaibonnet and Arborio, "weedy" scatters and regression lines refer to average values recorded in rice grown in presence of 10,20 or 40 plants $\mathrm{m}^{-2}$ of weedy rice. In the case of weedy rice, the plot refer to average values recorded at 10,20 or 40 plants $\mathrm{m}^{-2}$ of weedy rice density. At each sampling date, significant differences for $P \leq 0.05$ or $P \leq 0.01$ are indicated by the symbol "*” or “**”, respectively.

Aboveground Biomass. The evolution in time of the aboveground biomass partially reflected the trends observed for plant height. Nevertheless, the generally slender and weaker appearance of the plants in the 1998 experiment resulted in a significantly lower biomass both for cultivated and weedy rice.

The biomass produced by cultivar Thaibonnet recorded in the last samplings ranged from $6.6 \mathrm{~g} \mathrm{plant}^{-1}$ (at 0 weedy rice plants $\mathrm{m}^{-2}$ ) to 3.2 g plant ${ }^{-1}$ (at 40 plants $\mathrm{m}^{-2}$ ), and from 3.9 to 2.9 g plant $^{-1}$ in 1997 and 1998, respectively. In both years, the regressions obtained for the various conditions of competition with weedy rice were not significantly different. In the cultivar Arborio the biomass ranged from $15.4 \mathrm{~g} \mathrm{plant}^{-1}$ (at 0 weedy rice plants $\mathrm{m}^{-2}$ ) to $9.4 \mathrm{~g} \mathrm{plant}^{-1}$ (at 40 plants $\mathrm{m}^{-2}$ ), in 1997 , and from 8.7 to $8.1 \mathrm{~g}$ plant $^{-1}$, in 1998. Also for this cultivar, no significant differences were found between the growth patterns observed under the different competition conditions.

In weed rice, as observed for cultivars, the highest values were recorded in 1997 (Fig. 2). The biomass of weedy rice grown in competi- tion with Thaibonnet recorded at the last sampling averaged $26.3 \mathrm{~g} \mathrm{plant}^{-1}$ in 1997 and $11.3 \mathrm{~g}$ plant $^{-1}$ in 1998, corresponding to 5.2 and 3.4-fold the biomass of the cultivar (Tab. 1). At the same sampling time, the biomass of weedy rice grown in competition with Arborio averaged $30.3 \mathrm{~g}$ plant $^{-1}$ and 15.5 g plant $^{-1}$ in 1997 and 1998, respectively, corresponding to 2.5 and 1.8 -fold the cultivar biomass. As observed for plant height, and within each cultivar, weedy rice biomass growth was not significantly influenced by weedy rice density, neither in terms of growth pattern (no significant differences between regression curves were found) nor considering separately each sampling date. Weedy rice plants grown in Arborio generally produced more biomass than those grown in Thaibonnet.

For the last sampling dates, in particular, the average biomass of weedy rice grown in competition with Arborio was about 15\% higher, in 1997, and 37\% higher, in 1998, than that reached by weedy rice grown in Thaibonnet. Significant differences between weedy rice grown in competition with Thaibonnet or Arborio were found in the third sampling in 1997 and in the last sam- 

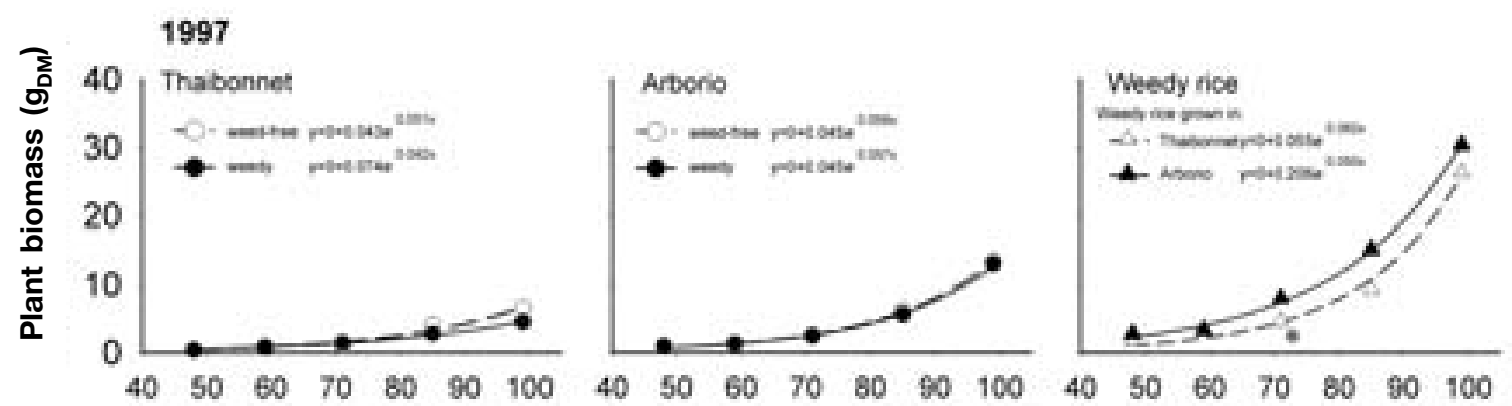

Days After Sowing (DAS)
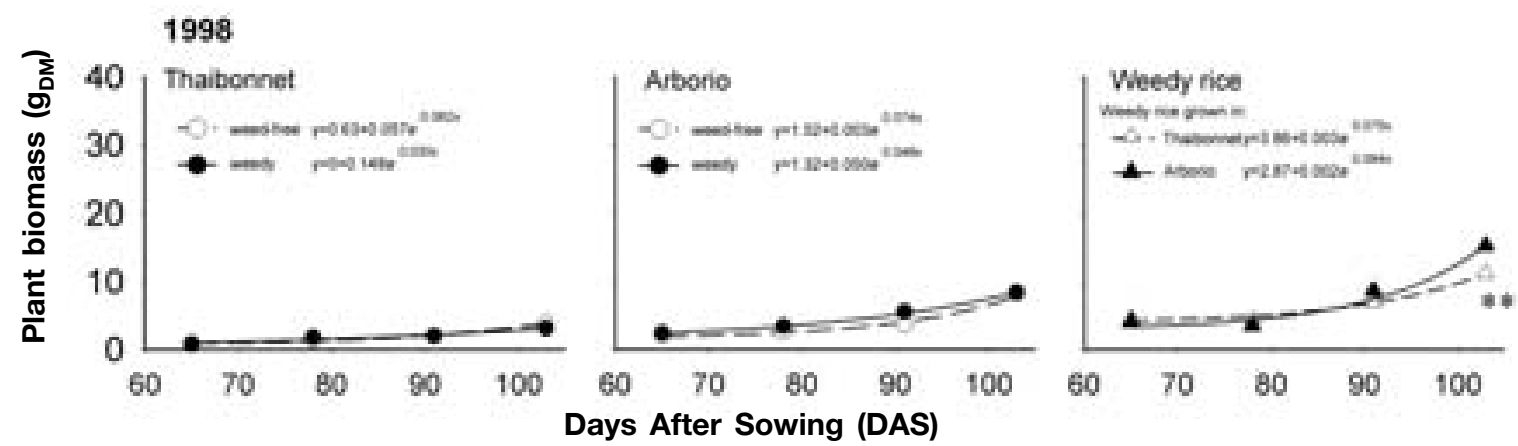

Figure 2. Aboveground biomass growth of Thaibonnet, Arborio and weedy rice in 1997 and 1998. In the case of Thaibonnet and Arborio, "weedy" scatters and regression lines refer to average values recorded in rice grown in presence of 10,20 or 40 plants $\mathrm{m}^{-2}$ of weedy rice. In the case of weedy rice, the plot refer to average values recorded at 10, 20 or 40 plants $\mathrm{m}^{-2}$ of weedy rice density. At each sampling date, significant differences for $P \leq 0.05$ or $P$ $\leq 0.01$ are indicated by the symbol "*” or “**”, respectively.

pling in 1998. However, in 1997 the curve fitting the biomass data evolution along the time of weedy rice grown in Arborio was significantly different from that of weedy rice grown in Thaibonnet, and resulted in higher estimated values for most of the growing period.

Tillering. The number of tillers of both cultivars and weedy rice was higher during 1997 than 1998.

The average number of tillers per plant in Thaibonnet ranged from 1.9 to 3.7 in 1997 and from 1.9 to 2.2 in 1998 (Tab. 1). Arborio showed a number of tillers slightly higher than that recorded in Thaibonnet, as this parameter ranged from 2.3 to 3.6 , in 1997, and from 2.4 to 2.8, in 1998.

In the weedy rice, the difference between the two years was larger, with this parameter ranging from 7.7 (1998) to 3.5 (1998) in weedy rice grown in Thaibonnet and from 9.4 (1997) to 5.0 (1998) in weedy rice grown in Arborio.

The weedy rice density had no effect on this parameter, both if the cultivars or the weed were considered. Weedy rice grown in Arborio showed a higher number of tillers per plant in both years, even though the difference was significant only in 1998.

Yield. In the second year, plots with Arborio showed severe lodging that occurred about 20 days before harvesting consequent to a storm. Visual scoring of lodging in Arborio plots showed no significant differences between treatments (data not shown). For this reason, yield data of Arborio plots referred to 1998 trial are not presented nor discussed hereafter.

In general, the rice yield was always affected by weedy rice competition (Fig. 3). At the highest weedy rice density, the yield losses averaged 49\%, in 1997, and 30\%, in 1998 .

Yield recorded in the control plots of Thaibonnet was $6779 \mathrm{~kg} \mathrm{ha}^{-1}$ (at 13\% moisture content) in 1997 and $5382 \mathrm{~kg} \mathrm{ha}^{-1}$ in 1998. The noninfested plots of cultivar Arborio gave a yield of $5088 \mathrm{~kg} \mathrm{ha}^{-1}$ in 1997. In Thaibonnet, the yield loss at 10 and 40 plants $\mathrm{m}^{-2}$ ranged from $25.7 \%$ 


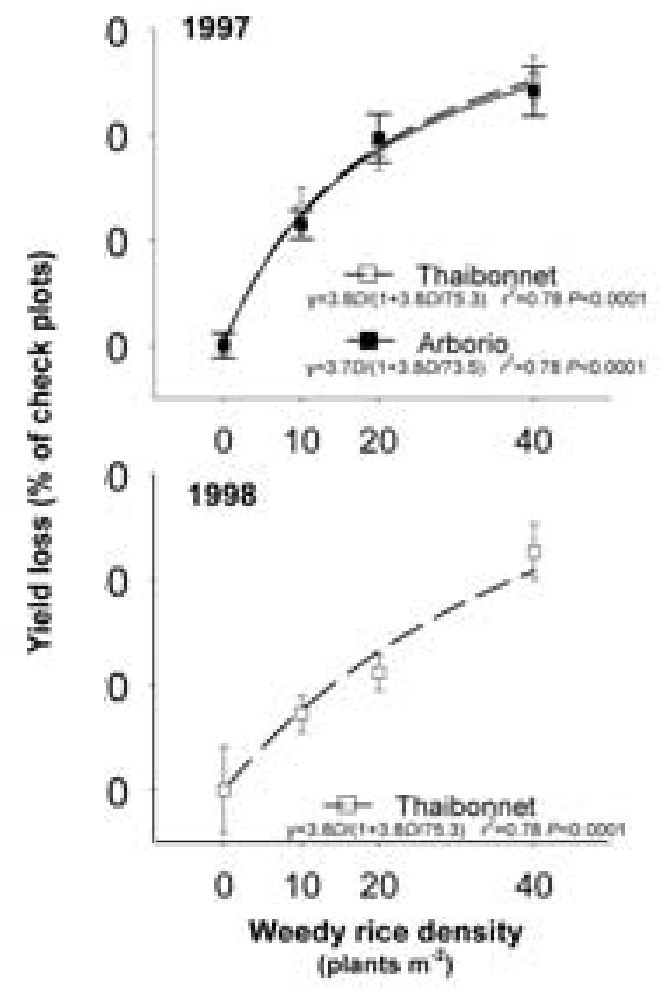

Figure 3. Rice yield losses recorded in the two years. Lines refer to the hyperbolic regression model. Bars represent the Standard Error.

to $50.5 \%$, in 1997 , and from $14.5 \%$ to $45.3 \%$ in 1998. In Arborio, the relative yield reduction at 10 and 40 plant $\mathrm{m}^{-2}$ ranged from $22.9 \%$ to $48.3 \%$, in 1997.

Significant hyperbolic relationships between yield loss and weedy rice density were observed in 1997 for both the cultivars. The estimated percent yield losses at very low weed density (parameter $i$ of Eq. 2) and at very high weed density (parameter $a$ ) and the standard error of both estimates were very similar between the cultivars.

In 1998, the hyperbolic model gave a significant explanation of the yield loss data in Thaibonnet. Compared to the previous year, the model predicted a yield loss at very high weed density of $100 \%$, but the estimate was affected by a higher uncertainty.

Yield Components. The rice yield components considered in the study (panicle density, number of filled grains per panicle and 1000-seed weight) were generally affected by weedy rice

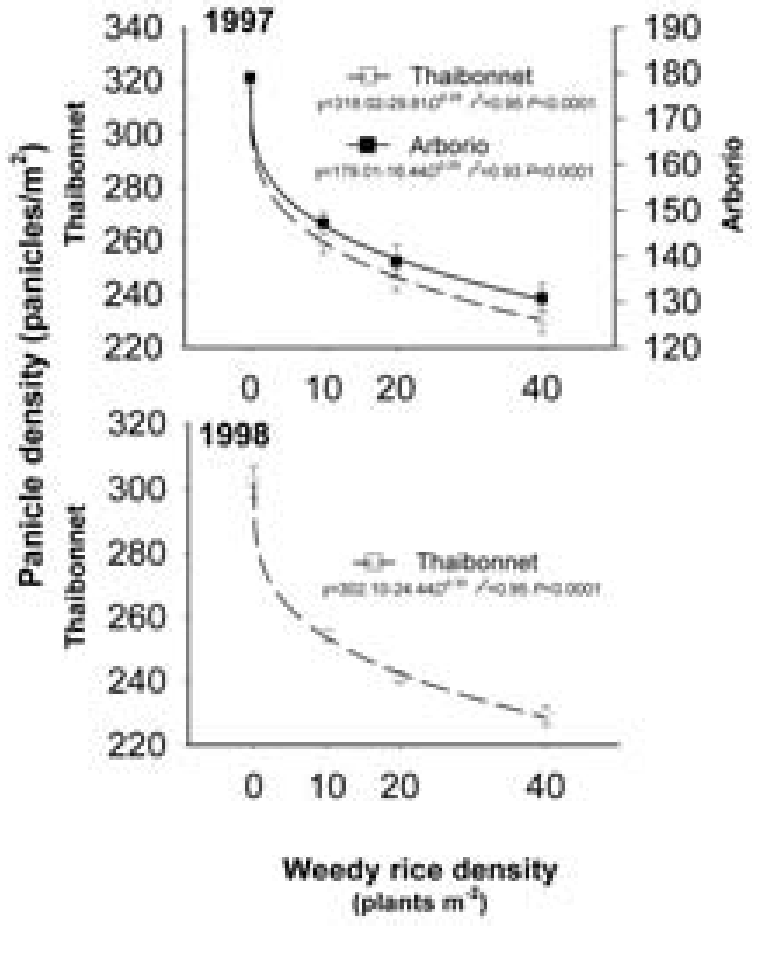

Figure 4. Relationship between weedy rice density and panicle density of cultivated rice. Bars represent the Standard Error.

density, even though the extent and strength of the relationships varied according to the cultivar and year.

The panicle density (Fig. 4) in control plots was about 320 (Thaibonnet) and 180 panicles $\mathrm{m}^{-2}$ (Arborio) in 1997, and 300 (Thaibonnet) panicles $\mathrm{m}^{-2}$ in 1998. In presence of 40 plants $\mathrm{m}^{-2}$ of weedy rice, the number of panicles $\mathrm{m}^{-2}$ fell from $76 \%$ to $73 \%$ of the values recorded in the control plots.

In all conditions, the selected model gave a good fitting to the data $\left(P<0.0001 ; r^{2} \geq 0.93\right)$. The reduction of panicle density as a function of the weedy rice density was particularly evident when control plots and plots with 10 plants $\mathrm{m}^{-2}$ of weedy rice were compared. For higher density conditions, the reduction of the number of panicles per $\mathrm{m}^{2}$ was less steep and almost linear.

The number of filled grains per panicle in control plots was about 88 (Thaibonnet) and 67 (Arborio), in 1997, and 82 (Thaibonnet) in 1998 (Fig. 5). The response of this variable to in- 


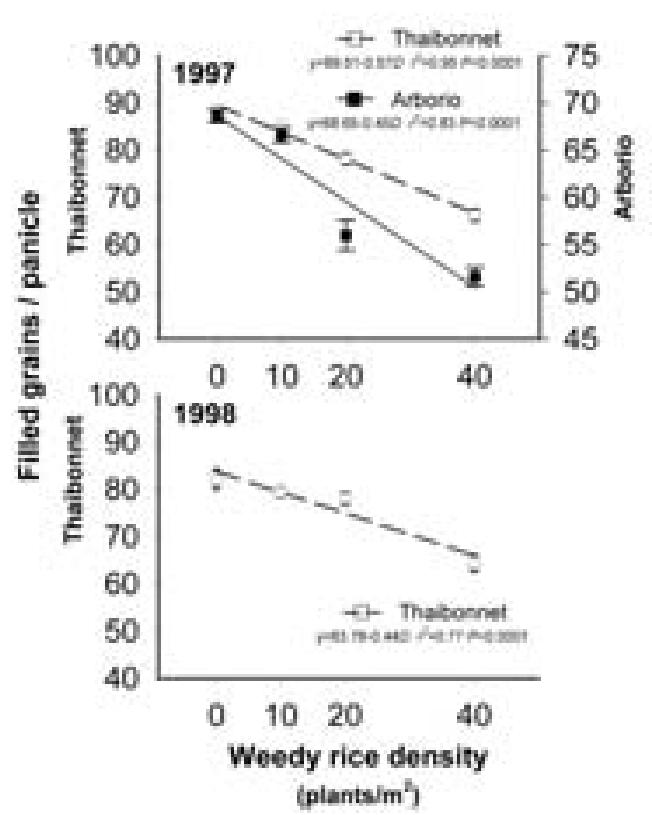

Figure 5. Relationship between weedy rice density and number of filled grains per panicle of cultivated rice. Bars represent the Standard Error.

creasing weedy rice densities was well described by a simple linear regression.

The 1000-seed weight was less affected by weedy rice density than the other yield components (Fig. 6), as the reduction at the highest competition conditions ranged from 4\% (Arborio 1998) to $10 \%$ (Thaibonnet 1998). The regressions fitting the data were generally poorer $\left(0.005<P<0.033 ; r^{2}=0.47-0.49\right)$.

\section{Discussion}

In both the cultivars included in this study, the temporal patterns of plant height and aboveground biomass were not significantly modified at the tested weedy rice densities. These results are partly in agreement with the information available from the literature. Several studies pointed out that the effects of weedy rice interference on dynamics of different growth parameters of rice can vary from not significant to strong, according to the experimental conditions (Montealegre and Clavijo, 1991; Kwon et al., 1991a; Estorninos et al., 2000, 2002; Eleftherohorinos et al., 2002). For instance, in this study a $5 \%$ of plant height reduction due to competition was recorded in Thaibonnet in 1997 only,

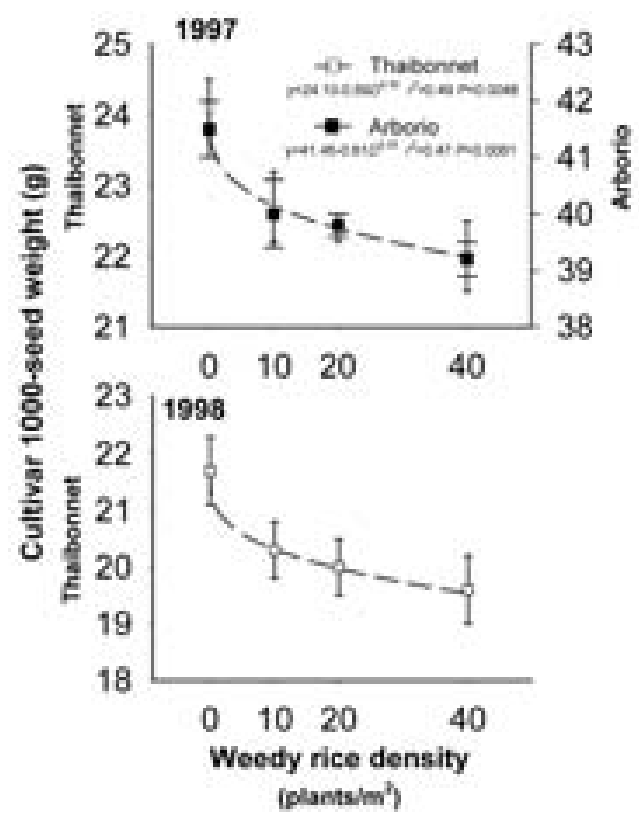

Figure 6. Relationship between weedy rice density and 1000 -seed weight of harvested paddy. Bars represent the Standard Error.

while Kwon et al. (1991a) reported a reduction of $4.3 \%$ in the cultivar Lemont and $6 \%$ in the cultivar Newbonnet, with an infestation of 10 plants $\mathrm{m}^{-2}$.

Weedy rice density variably affected the final values reached by plant height and aboveground biomass. On average, values of both parameters were reduced as the weedy rice density increased, even though the effect was significant only in some cases. Between the two growth parameters, the final biomass was generally more affected by weedy rice interference. With the exception of Arborio in 1998, where the results were affected by crop lodging, the final biomass of rice plants grown at the highest competition level was reduced by 26 to $52 \%$ in comparison to the values recorded in the untreated plots. In the case of final plant height, the reduction was from 1.5 to $5 \%$ only. The plant biomass decrease was generally accompanied by a concurrent reduction of the number of tillers per plant.

The yield recorded in both years in the control plots was remarkably higher in Thaibonnet than in Arborio, despite the lower biomass per plant found for the first variety. This result was expected and reflects the different features, and 
the average harvest index in particular, which characterize the two varieties. Notwithstanding their different yield potential, both cultivars showed up to $50 \%$ of yield loss, in relation to the weedy rice density. The relationship between weedy rice density and yield loss was particularly evident and consistent between the cultivars during the first year. In this case, the hyperbolic model used to fit the data predicted a yield of more than $73 \%$ at very high weedy rice density. The recorded yield reduction values are in agreement with the findings of similar studies cited in the literature, even though higher yield losses have been sometimes reported for similar weedy rice densities (Diarra et al., 1985a, 1985b; Kwon et al., 1991a; Fischer and Ramirez, 1993).

Different studies showed that weedy rice infestation can result in a reduction of the panicles per plant, spikelets per panicle and filled grains per panicle ratios, panicle length and grain dimension (Leitao-Filho et al., 1972; Kwon et al., 1991b). According to Pantone et al. (1992), in particular, the panicles per plant and spikelets per panicle ratios resulted to be the most sensitive factors to weedy rice density.

The results of this study suggest that the cultivated rice reacts to weedy rice interference by reducing in part the vegetative growth of the plant (mainly in terms of plant biomass) and the allocation of biomass towards the reproductive organs.

The two cultivars showed similar relative yield losses and yield component reductions at the same weedy rice infestation level. Several factors, likely organized in a complex system of interactions, could be involved in explaining how this similarity occurred even if the two cultivars show notable differences in terms of competition-related traits (e.g. size, earliness, plant biomass, etc.). The analysis of these factors, that should require a specific research, was beyond the objectives of this paper. Yet, the results of this study suggest that this similarity could be in part explained by the different growing behaviour that the weedy rice showed when grown with the two varieties. On average, weedy rice plants grew taller and produced more biomass when they were in competition with the taller and supposedly more competitive variety Arborio. The adaptability of weedy rice to the competition condition is a potential ecological advantage, which might explain the success of the spreading of the weed. This feature of the weed greatly affects the possibility of its successful management through the choice of varieties supposedly having a potential suppressive capacity because of their tall size or early growth. This result is apparently in contradiction with the findings of several studies according to which the morphological traits and growth behaviour is essential for the exploitation of the competitive ability of the crop, according to the principles of integrated weed management strategies (Shaw, 1982; Altieri and Liebman, 1987). According to an old study of Oka (quoted by Harper, 1964), there was no regular correlation between the competitive ability of Indica-Japonica crosses and rice, and plant height, maturity, size, habit of growth (erect or prostrate), or grain yield. The list of characters studied, however, is restricted and does not include extent and depth of the root system, which has not been taken into consideration both in that and in our study. A recent study of Burgos et al. (2006) pointed out that weedy rice was more efficient than the cultivated variety "Drew" in uptaking nitrogen and in the use of it for biomass production. The authors suggest that the reasons for this behaviour are essentially a bigger root system and the continuous production of tillers throughout the growing season in weedy rice, which results in the maintenance of a diffusion gradient of nitrogen to the young tillers and eventually in a greater nitrogen accumulation in the plant and in more foliage. These findings not only indicate a stronger competitive ability of weedy rice in comparison to cultivated varieties, but suggest also that the control of weedy rice is essential in order to optimize the efficiency of nitrogen fertilization.

\section{References}

Abud J.K. 1989. Efeitos competitivos do arroz vermelho nos componentes do rendimento e rendimento de graos em casca na cultivar de arroz BR-IGRA 412. Lavoura Arrozeira, 42:11-12.

Altieri M.A., Liebman M. 1987. Weed management: ecological guidelines. In: Altieri M.A. and Liebman M. (eds.): Weed Management in Agroecosystems: Ecological Approaches. CRC Press, Boca Raton, FL, 331337. 
Baker J.B., Sonnier E.A., Shrefler J.W. 1986. Integration of molinate use with water management for red rice (Oryza sativa) control in water-seeded rice (Oryza sativa). Weed Science, 34:916-922.

Burgos N.L., Norman R.J., Gealy D.R., Black H. 2006. Competitive $\mathrm{N}$ uptake between rice and weedy rice. Field Crops Research, 99:96-106.

Chow G.C. 1960. Tests of equality between sets of coefficients in two linear regressions. Econometrica, 28:591-605.

Cousens R. 1985. A simple model relating yield loss to weed density. Annals of Applied Biology, 107:239-252.

Dadi T., Engels J.M.M. 1986. Exploration and collection of wild rice in Ethiopia. PGRC/E ILCA Germplasm Newsletter, 12:9-11.

Diarra A., Smith R.J., Talbert R.E. 1985a. Growth and morphological characteristics of red rice (Oryza sativa) biotypes. Weed Science, 33:310-314.

Diarra A., Smith R.J., Talbert R.E. 1985b. Interference of red rice (Oryza sativa L.) with rice. Weed Science, 33:644-649.

Eleftherohorinos I.G., Dhima K.V., Vasilakoglou I.B. 2002. Interference of red rice in rice grown in Greece. Weed Science, 50:167-172.

ENR. 1998. XXI Relazione sulle prove dimostrative 1998. 69. Milano: Ente Nazionale Risi.

Estorninos L.E., Gealy D.R., Talbert R.E. 2000. Interference between red rice and rice in a replacement series study. Arkansas Agricultural Experiment Station Mimeograph Series, 476:463-468.

Estorninos L.E., Gealy D.R., Talbert R.E. 2002. Growth response of rice (Oryza sativa) and red rice (Oryza sativa) in a replacement series study. Weed Technology, 16:401-406.

FAO. 2000. Global Workshop on Red Rice Control. 155. Plant Production and Protection Division. Rome, Varadero, Cuba: Food and Agriculture Organization of the United Nations.

Federici M.T., Vaughan D., Tomooka N., Kaga A., Wang X.W., Doi K., Francis M., Zorrilla G., Saldain N. 2001. Analysis of Uruguayan weedy rice genetic diversity using AFLP molecular markers. Electronic Journal of Biotechnology, 4:5-6.

Ferrero A., Vidotto F., Balsari P., Airoldi G. 1999. Mechanical and chemical control of red rice (Oryza sativa L. var. sylvatica) in rice (Oryza sativa L.) preplanting. Crop Protection, 18:245-251.

Fischer A.J., Ramirez A. 1993. Red rice (Oryza sativa): competition studies for management decisions. International Journal of Pest Management, 39:133-138.

Fleck N.G., Agostinetto D., Galon L., Schaedler C.E. 2008. Competitividade relativa entre cultivares de arroz irrigado e bio_tipo de arroz-vermelho. Planta Daninha, 26:101-111.

Harlan J.R. 1973. Genetic resources of some major field crops in Africa. In: Survey of crop genetic resources in their centres of diversity. First report. FAO/IBP, Rome, Italy, 45-64.
Harper J.L. 1964. The nature and consequence of interference amongst plants. In: Genetics Today, Proceedings of the 11th International Genetics Conference, 1963, The Hague, The Netherlands, 465-481.

Hoagland R.E., Paul R.N. 1978. A comparative SEM study of red rice and several commercial rice (Oryza sativa) varieties. Weed Science, 26:619-625.

Holm L., Doll J., Pancho J., Herbergher J. 1997. World weeds: natural histories and distribution. John Wiley \& Sons Inc., New York.

Jairo Clavijo P., Baker J.B. 1988. Germinacion, emergencia y crecimiento temprano de arroz rojo y cuatro variedades de arroz. Agronomia Colombiana, 5:3-7.

Katayama T.C., Sumi A. 1995. Studies on agronomic traits of African rice (Oryza glaberrima Steud) .3. Some grain morphological aspects of domestication and decrement. Japanese Journal of Crop Science, 64:807-814.

Kwon S.L., Smith R.J., Talbert R.E. 1991a. Interference of red rice (Oryza sativa) densities in rice (O. sativa). Weed Science, 39:169-174.

Kwon S.L., Smith R.J., Talbert R.E. 1991b. Interference durations of red rice (Oryza sativa) in rice (O. sati$v a)$. Weed Science, 39:363-368.

Kwon S.L., Smith R.J., Talbert R.E. 1992. Comparative growth and development of red rice (Oryza sativa) and rice (O. sativa). Weed Science, 40:57-62.

Leitao-Filho H.F., Banzatto N.V., Azzini L.E., Guimaraes G. 1972. Estudos de competicao entre o arroz vermelho e o arroz cultivado. Bragantia, 31:249-258.

Montealegre S.F., Clavijo P.J. 1991. Analisis de la competencia entre tres tipos de arros rojo y la variedad Oryzica 1. Agronomia Colombiana, 8:342-349.

Pantone D.J., Baker J.B. 1991a. Reciprocal yield analysis of red rice (Oryza sativa) competition in cultivated rice. Weed Science, 39:42-47.

Pantone D.J., Baker J.B. 1991b. Weed-Crop Competition Models and Response-Surface Analysis of Red Rice Competition in Cultivated Rice - a Review. Crop Science, 31:1105-1110.

Pantone D.J., Baker J.B., Jordan P.W. 1992. Path-Analysis of red rice (Oryza sativa L.) competition with cultivated rice. Weed Science, 40:313-319.

Seefeldt S.S., Jensen J.E., Fuerst E.P. 1995. Log-Logistic analysis of herbicide dose-response relationships. Weed Technology, 9:218-227.

Shaw W.C. 1982. Integrated weed management system technology for pest management. Weed Science, 30 (supplement): 2-12.

Tarditi N., Vercesi B. 1993. Il riso crodo: un problema sempre più attuale in risicoltura. Informatore Agrario, 43:91-95.

USDA and ARS. 2001. National Genetic Resources Program. Germplasm Resources Information Network (GRIN). Vol. September 2001. National Germplasm Resources Laboratory, Beltsville, Maryland. 